\title{
Cell-penetrating peptides as a promising tool for delivery of various molecules into the cells
}

\author{
Jaroslaw Ruczynski ${ }^{{ }^{*}}$, Piotr M. Wierzbicki ${ }^{2 *}$, Marzena Kogut-Wierzbicka ${ }^{2}$, \\ Piotr Mucha ${ }^{1}$, Kamila Siedlecka-Kroplewska ${ }^{2}$, Piotr Rekowski ${ }^{1}$ \\ ${ }^{1}$ Faculty of Chemistry, University of Gdansk, Gdansk, Poland \\ ${ }^{2}$ Chair and Department of Histology, Medical University of Gdansk, Gdansk, Poland \\ "Both authors equally contributed to this paper
}

\begin{abstract}
Many biologically active compounds, including macromolecules that are used as various kinds of drugs, must be delivered to the interior of cell or organelles such as mitochondria or nuclei to achieve a therapeutic effect. However, very often, lipophilic cell membrane is impermeable for these molecules. A new method in the transport of macromolecules through the cell membrane is the one based on utilizing cell-penetrating peptides (CPPs). Invented 25 years ago, CPPs are currently the subject of intensive research in many laboratories all over the world. CPPs are short compounds comprising up to 30 amino acid residues, which penetrate the cell membrane but do not cause cell damage. Additionally, CPPs can transfer hydrophilic molecules (peptides, proteins, nucleic acids) which exceed their mass, and for which the cell membrane is generally impermeable. In this review, we concentrate on the cellular uptake mechanism of CPPs and a method of conjunction of CPPs to the transported molecules. We also highlight the potential of CPPs in delivering various kinds of macromolecules into cells, including compounds of therapeutic interest. (Folia Histochemica et Cytobiologica 2014, Vol. 52, No. 4, 257-269)
\end{abstract}

Key words: cell-penetrating peptides; membrane transduction peptides; covalent and noncovalent delivery strategy; endocytosis; anti-cancer drug delivery

\section{Introduction}

Because of the limitations of currently known drug delivery systems, mainly their low efficacy in overcoming the barrier of the cell membrane, there is a necessity to find new methods which efficiently and effectively increase the possibility of transport of protein molecules into the cell interior. The main problem is the penetration of compounds into the lipophilic cell membrane as the hydrophobic nature of the plasma

Correspondence address: Jaroslaw Ruczynski, Ph.D.

Faculty of Chemistry

University of Gdansk

Wita Stwosza Str. 63, 80-308 Gdansk

tel.: +48585235431

e-mail: jaroslaw.ruczynski@ug.edu.pl membrane results in its impermeability for the majority of hydrophilic, biologically active molecules. To overcome this problem, various techniques of cell membrane penetration, such as electroporation, microinjection, viral vectors, or liposomal encapsulation, have been proposed in recent years.

These methods, however, are not perfect, because of low efficiency of transport and cytotoxicity (to some extent). A method involving cell-penetrating peptides (CPPs) constitutes a new technique of cell membrane penetration based on the transport of macromolecules through the cell membrane. Due to the lack of permeability of cell membrane for hydrophilic biomolecules, the discovery of CPPs can be regarded as an important step forward in increasing the availability of therapeutically important substances such as peptides, proteins, or nucleic acids, however, of low membrane permeability. 


\section{Definition and history of cell-penetrating peptides}

Cell-penetrating peptides are short compounds, comprising up to 30 amino acid (aa) residues, which can penetrate the plasmalemma as well as mitochondrial and nuclear membranes, without causing any damage to the membranes [1]. CPPs were identified for the first time during the studies by two independent groups on the ability of cell penetration by HIV-1 trans-activating protein Tat $[2,3]$. They synthesized shorter analogs of 86-aa Tat protein, demonstrating a very high efficiency of penetration by Tat fragments of length between 21 and 48 aa or 58 aa. In 1991, Prochiantz et al. showed that synthetic 60 -aa peptide (pAntp) corresponding to the Antennapedia homeodomain protein of Drosophila was internalized by nerve cells which resulted in morphological changes of neuronal cell cultures [4].

This finding served as the basis for obtaining the first CPP in 1994 - oligopeptide corresponding to C-terminal fragment of the third helix of the Antennapedia homeodomain consisted of 16 aa residues known as penetratin (RQIKIYFQNRRMKWKK) [5]. During the course of the experiments, it was noted that the reduction of oligopeptide length to 15 aa abolished its ability to penetrate into cells. Then, in 1998, Lebleu et al. identified the shortest Tat peptide sequence necessary for cell penetration - ${ }^{47}$ YGRKKRRQR [6]. Both of the abovementioned peptides correspond in their sequence to RNA/DNA-binding proteins. It was demonstrated that the transport of synthetic peptides was observed also at a temperature of approximately $4^{\circ} \mathrm{C}$, which, according to the authors, precluded endocytosis as a mechanism of cell penetration $[5,6]$.

Depending on their chemical structure, CPPs may be amphipathic or may exhibit highly cationic properties and are usually rich in amino acids such as arginine (Arg) and lysine (Lys). It has been proven that they are able to translocate various substances into the cells, including both low and high molecular weight molecules such as polysacharides, peptides, proteins, or nucleic acids [7]. The mechanism of penetration of CPPs into the cell membrane has not been completely understood. Previous studies reported different kinds of peptide transport depending on the class to which peptides belong to. Since their discovery, CPPs have been studied as carriers of many bioactive components penetrating cell membranes of different cell types [8].

\section{CPP classification}

Cell-penetrating peptides are currently classified in several ways, depending on their individual properties.
In literature, instead of cell-penetrating peptides, terms such as 'protein transduction domains' (PTDs) and 'membrane translocation sequence' (MTS) are also used. CPPs can be classified by the functions of their original proteins, their uptake mechanisms, intracellularly evoked reactions, and their chemical properties. They can also be divided according to whether they are receptor-mediated or non-receptor-mediated [9]. On the basis of their origin, CPPs can be classified into four groups: protein-derived CPPs, model peptides, chimeric CPPs, and synthetic CPPs. Protein-derived CPPs are usually short peptide sequences responsible for translocation, such as the Tat(47-57) fragment derived from the trans-activating protein. PTDs are primarily referred to Tat and penetratin.

Model peptides imitate the structure of the known CPPs - amphipathic MAP peptide, for example. Chimeric peptides are a combination of hydrophilic and hydrophobic peptide fragments of different origins. In this case, transportan (TP), a 27 -aa long molecule formed as a result of combination of galanin neuropeptide and mastoparan, and its shorter 21-aa analog, transportan 10 (TP10), are classic examples [10]. Peptides of polyarginine family belong to the group of synthetic CPPs [11].

CPPs can also be divided into three classes, including different peptide sequences and lipid-binding properties as shown in Table 1 . These groups are primary amphipathic peptides, secondary amphipathic peptides, and 'non-amphipathic' cationic peptides. Primary amphipathic CPPs (paCPPs) such as TP and TP10 usually consist of more than 20 aa residues and their primary structure contains hydrophilic and hydrophobic fragments.

Previous studies indicated mechanisms of membrane penetration by these peptides, along with the formation of pores, 'carpet' model, and inverted micelles in the membrane lipid bilayer [11]. In comparison with the primary peptides, secondary amphipathic peptides ( $\mathrm{saCPPs}$ ) such as penetratin, pVEC, and M918 contain fewer amino acid residues $[5,8,12]$. Their amphipathic properties are activated when $\alpha$-helix or $\beta$-sheet is formed during the interaction with the membrane phospholipids [13]. Non-amphipathic peptides (naCPPs) are short and contain mainly cationic amino acids, e.g. Arg. Tat and $\operatorname{Arg}_{9}$ are, among others, included in naCPPs group $[6,14]$. naCPPs and saCPPs are both less toxic than paCPPs, and higher concentrations or application of a transmembrane potential seems to be required to make the membrane unstable, both in the cell and in membrane model systems. It has been shown that acylation of these cationic peptides to make them more 
hydrophobic is a way to induce membrane leakage by this class of CPPs $[13,15]$. The fourth class of CPPs are peptides derived from hydrophobic sequences of proteins which naturally interact with plasma membrane, e.g. integrin $\beta 3$-fragment [16], Hepatitis B virus translocation motif [17] or calcitonin fragment (Table 1) [18].

\section{Cellular uptake mechanisms of cell-penetrating peptides}

The mechanism of translocation through the cell membrane, despite some common features (e.g., total positive charge of the molecule) described for different CPPs, is different for each peptide depending on the class which a particular CPP belongs to. It has been observed that most CPPs may use different mechanisms of membrane translocation depending on the type and substitution position of a fluorophore as well as on the type of the transporting molecule. Molecular pathways of penetration and translocation across the cell membrane have not been still fully elucidated. Two major mechanisms of permeation through membranes have been proposed: direct membrane translocation without energy input and endocytosis.

\section{Direct translocation}

The results of internalization of CPPs into cells even at low temperatures excluded endocytosis as the main mechanism of transport of peptides into the cell and suggested the existence of an alternative mechanism which required no energy [19]. Such transport mechanism was naturally observed for CPPs isolated from venoms: mastoparan [20] from $V$. lewisii wasp or crotamine [21] from rattlesnake, which interact directly with cell membrane (Table 1). Other studies using peptides containing D-amino acids and peptides with retro-sequence showed similar (or better, in the case of D-amino acids) effectiveness as their equivalents containing L-amino acids or peptides with unmodified sequences, confirming the lack of receptor-specific endocytosis during cellular introduction [22, 23].

The concept of direct translocation requiring no energy input includes the evaluation of mechanisms observed with the contribution of inverted micelles, formation of pores, and the 'carpet' model [24, 25]. All these mechanisms are based primarily on the interaction of positively charged CPPs with negatively charged components of the cell membrane such as heparan sulfate and phospholipid bilayer. This process requires permanent or temporary destabilization of the membrane caused by peptides present in the lipid layer of the membrane. Further internalization depends on the concentration, the peptide's amino acid sequence, and the lipid composition of the membrane as well. Direct translocation is most likely at high CPP concentration, in particular for primary amphipathic peptides such as TP and its analogs or MPG $\alpha$ peptide (Table 1) [26-28].

The mechanism involving inverted micelles is a model suggested for the direct transport of penetratin [5]. This mechanism assumes local disorder of the phospholipid bilayer, resulting in the formation of inverted hexagonal structures (inverted micelles). It was found that peptides are encapsulated in the hydrophilic environment of micelle interior until the reverse process resulting in the destabilization of the inverted micelle occurs, and, consequently, a peptide is released into the cell interior. This was confirmed by the results obtained from experiments using nuclear magnetic resonance (NMR) [29]. This mechanism is driven mainly by the CPP gradients on both sides of the cell membrane [30].

The 'carpet' model explains the possibility of internalization of small hydrophilic peptides. Additionally, despite the interactions between positively charged CPP components and negatively charged lipid membrane components, hydrophobic amino acid residues such as tryptophan, along with hydrophobic elements of the membrane, are also involved in this mechanism. Therefore, this kind of cell membrane penetration and delivery of molecules are less likely for strongly cationic peptides such as Tat, $\operatorname{Arg}_{8}$ or $\mathrm{Lys}_{8}$ [31]. Experiments using NMR and electron microscopy revealed the formation of other structures than inverted micelles when Tat, $\mathrm{Arg}_{8}$, or $\mathrm{Lys}_{8}$ were used [32].

Analogous to the mechanism of membrane structure disorder resulting in the formation of inverted micelles observed during internalization of peptides and toxins, alternative mechanisms of CPP translocation were also proposed. Hence, the mechanism of penetration into the cell membrane involving pore formation includes two models - 'barrel-stave' model and 'toroidal' model. In the 'barrel-stave' model, peptides possessing the structure of $\alpha$-helix form a bundle in the membrane with a channel at its center. It resembles a barrel constructed of staves. The staves are CPPs' fragments inserted into membrane. Hydrophobic regions of the helix are localized in the region of the membrane lipids. In addition, the hydrophilic region of CPP is bound to the hydrophilic heads of phospholipids forming an inner part of a gap.

In the 'toroidal' model of pore formation, peptides penetrate into the lipid bilayer of the membrane and cause bending of the lipid monolayer into the interior forming a hydrophilic gap in plasma membrane. In 
Table 1. Classification of CPPs according to their origin and biochemical properties according to Reissmann [9]

\begin{tabular}{|c|c|c|c|}
\hline $\begin{array}{l}\text { CPP } \\
\text { classification }\end{array}$ & CPP name & Amino acid sequence & $\begin{array}{l}\text { Amino } \\
\text { acid } \\
\text { length }\end{array}$ \\
\hline \multicolumn{4}{|c|}{ According to origin } \\
\hline \multicolumn{4}{|c|}{ Peptides derived from protein transduction domains } \\
\hline & $H I V$ Tat $(47-57)$ & YGRKKRRQRRR & 11 \\
\hline & Penetratin & RQIKIWFQNRRMKWKK & 16 \\
\hline & Transportan (TP) & GWTLNSAGYLLGKINLKALAALAKKIL & 27 \\
\hline & VP-22 & DAATATRGRSAASRPTERPRARARSASRPRRPVD & 34 \\
\hline \multicolumn{4}{|c|}{ Ligands for the subfamily of integrins } \\
\hline & RGD peptides $\alpha v \beta 3$ & RGD-Temporin-LA, RGD-Dye & \\
\hline & RGD peptide & Cyclo(RGDfK); cyclo(RGDyK) & \\
\hline \multicolumn{4}{|c|}{ Venoms and toxins } \\
\hline & Mastoparan & INLKALAALAKKIL-amide & 14 \\
\hline & Mellitin & GIGAVLKVLTTGLPALISWIKRKRQQ-amide & 26 \\
\hline & $\begin{array}{l}\text { Rattle snake toxin (Crotamine) } \\
\text { derived NrTP6 }\end{array}$ & YKQSHKKGGKKGSG & 14 \\
\hline \multicolumn{4}{|c|}{ Histones and histidine peptides } \\
\hline & $\mathrm{H} 1, \mathrm{H} 2 \mathrm{~A}, \mathrm{H} 2 \mathrm{~B}, \mathrm{H} 3, \mathrm{H} 4$ & Single histones or mixtures of them & \\
\hline & Histidine-rich CPP & HR9: C-HHHHH-RRRRRRRRR-HHHHH-C & \\
\hline \multicolumn{4}{|c|}{ Partial sequences of tumor selective enzyme } \\
\hline & Redox protein azurin ' $p 18$ ' & Azurin Leu $^{50}-$ Gly $^{67}$ : LSTAADMQGVVTDMGASG & 18 \\
\hline \multicolumn{4}{|c|}{ Bacterial Peptides } \\
\hline & $\operatorname{Bac} 7(1-35)$ & RRIRPRPRLPRPRPRPLPFPRGPRPIPRPLPFP & 33 \\
\hline & Bac7 (5-35) & PRPRLPRPRPRPRPLPFPRGPRPIPRPLPFP & 31 \\
\hline \multicolumn{4}{|c|}{ According to chemical structure } \\
\hline \multicolumn{4}{|c|}{ Amphipathic peptides } \\
\hline & Transportan $10(T P 10)$ & AGYLLGKINLKALAALAKKIL-amide & 21 \\
\hline & Pep-1 & Ac-KETWWETWWTEWSQPKKKRKV-NH-CH${ }_{2}-\mathrm{CH}_{2}-\mathrm{SH}$ & 21 \\
\hline & $\mathrm{MPG} \alpha$ & $\begin{array}{l}\text { Ac-GALFLAFLAAALSLMGLWSQPKKKRKV-NH-CH- } \\
{ }_{2}-\mathrm{CH}_{2}-\mathrm{SH}\end{array}$ & 27 \\
\hline & CADY & Ac-GLWRALWRLLRSLWRLLWKA-NH- $\mathrm{CH}_{2}-\mathrm{CH}_{2}-\mathrm{SH}$ & 20 \\
\hline & Pepfect6 & Stearyl-AGYLLGK( $\varepsilon$-TMQ)INLKALAALAKKIL & 21 \\
\hline & MAP & KALAKALAKALA & 12 \\
\hline & KLA sequence & Acetyl-KLALKLALKALKAALKLA-amide & 18 \\
\hline \multicolumn{4}{|c|}{ Cationic peptides } \\
\hline & Oligoarginines $\left(\operatorname{Arg}_{9}-\operatorname{Arg}_{12}\right)$ & RRRRRRRRR - RRRRRRRRRRRR & $9-12$ \\
\hline & $H I V \operatorname{Tat}(47-57)$ & YGRKKRRQRRR & 11 \\
\hline & Penetratin & RQIKIWFQNRRMKWKK & 16 \\
\hline & FHV coat (35-49) & RRRRNRTRRNRRRVR-amide & 15 \\
\hline & $\begin{array}{l}\text { Chimeric dermaseptin S4 and SV40 } \\
\text { 'S4 } 4_{13}-\mathrm{PV} \text { ' }\end{array}$ & ALWKTLLKKVLKAPKKKRKVC & 21 \\
\hline & $\begin{array}{l}\text { Herpes simplex virus transcription } \\
\text { factor }(267-300) \text { VP22 }\end{array}$ & DAATATRGRSAASRPTERPRAPARSASRPRRPVE & 34 \\
\hline \multicolumn{4}{|c|}{ Hydrophobic peptides } \\
\hline & $\begin{array}{l}\text { Kaposis sarcoma fibroblast growth } \\
\text { factor Kaposi } F G F\end{array}$ & AAVALLPAVLLALLAP & 16 \\
\hline & $\begin{array}{l}\text { Signal sequence of Ig light chain } \\
\text { from Caiiman crocodylus }\end{array}$ & MGLGLHLLVLAAALQGAMGLGLHLLLAAALQGA & 33 \\
\hline & Integrin $\beta 3$-fragment & VTVLAGALAGVGVG & 14 \\
\hline & Fusion sequence HIV-1 gp41(1-23) & GALFLGFLGAAGSTMGA & 17 \\
\hline & Hepatitis B virus translocation motif & PLSSIFSRIGDP & 12 \\
\hline & $\begin{array}{l}\text { Human calcitonin partial sequence } \\
\text { 9-32, } h C T(9-32)-b r\end{array}$ & $\begin{array}{l}\text { LGTYTQDFNK(X)FHTFPQTAIGVGAP-amide } \\
\text { X: PKKKRKVEDPGVGFA }\end{array}$ & 41 \\
\hline
\end{tabular}




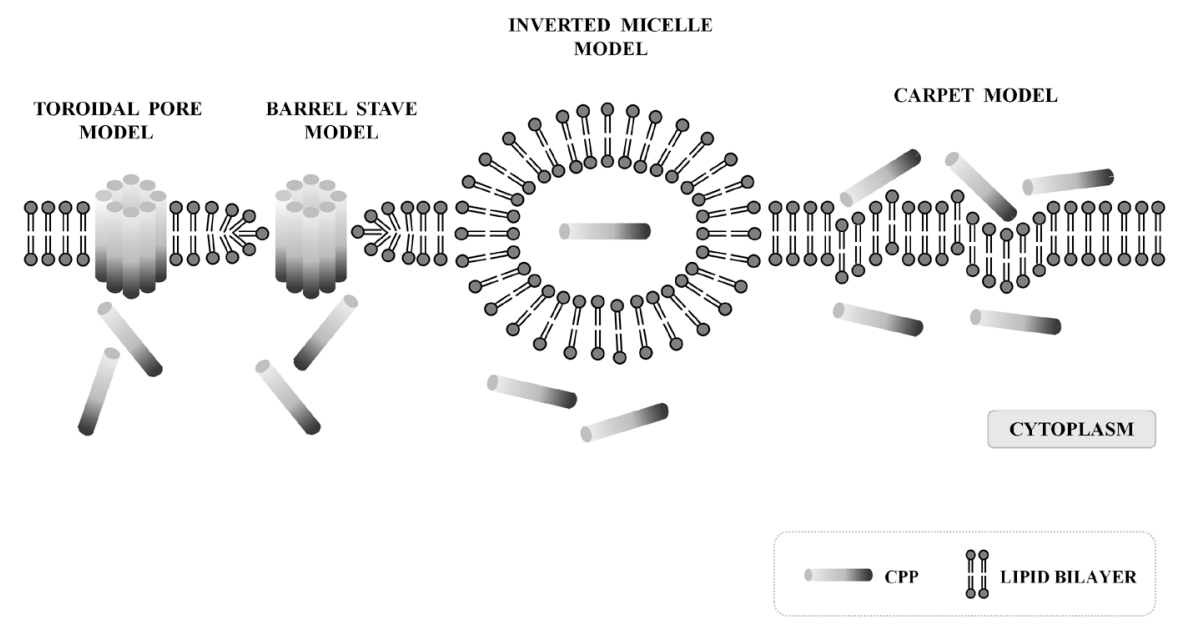

Figure 1. Proposed mechanisms of direct translocation of CPP through the cell membrane as proposed by Trabulo et al. [19]

the gap, phospholipids' heads and peptides are found. CPPs involved in this model of cellular introduction, demonstrate the possibility of $\alpha$-helix structure formation. TP and mastoparan exhibit lytic and antimicrobial properties $[33,34]$ and by the formation of a pore, they cause leakage of protons, metal ions, and proteins, which results in cell death. In the 'toroidal' model, polar peptide fragments are bound to the polar heads of phospholipid groups, as shown in Figure 1. This model is different from the 'barrel-stave' model in that the peptides are always bound to phospholipid heads, even during penetration through the lipid layer.

In both models, pores are formed when the concentration of the peptide exceeds a threshold value which varies depending on the CPP $[35,36]$. In the 'toroidal' model, pore diameter is also important; for example, in case of mastoparan the translocation of particles sized $<1000$ Da into the cell interior was observed [25]. Due to pore formation, amphipathic CPPs are more cytotoxic in comparison to peptides that act according to other mechanisms of cell penetration, such as penetratin or oligo-arginine $[37,38]$.

In the 'carpet' or adaptive translocation model, peptides do not penetrate into the lipid bilayer, but accumulate on its surface. They are electrostatically bound to the hydrophilic heads of phospholipid molecules in many locations, covering the surface of the cell membrane. Such 'carpet' arrangement of peptides on the surface of the membrane causes its destabilization. The interactions between negatively charged phospholipids and cationic CPPs induce covering of the cell membrane by CPPs and its further thinning. When the concentration of the peptide exceeds a threshold value, translocation of CPP is observed [38]. $\mathrm{Arg}_{9}$, which exhibits over a hundred times higher translocation efficiency in comparison to the corresponding peptides
$\mathrm{His}_{9}, \mathrm{Lys}_{9}$, and deca-ornithine, mainly participates in the adaptive translocation model $[22,39]$.

The important role of the guanidine group of Arg was also confirmed via the analysis of penetration of synthetic oligomers of Arg composed of D-amino acids or polyguanidine peptoids containing at least seven guanidine groups [22]. It has been suggested that Tat also penetrates into the cell according to the 'carpet' model, which is related to the presence of guanidine groups including CPP, as well as interactions between Tat and phosphate groups of phospholipid bilayer $[22,40]$. The membrane potential serves as a driving mechanism in the 'carpet' model. The inhibition of $\operatorname{Arg}_{9}$ penetration through cell membranes was observed after incubation of cells in a buffer containing isotonic concentration of $\mathrm{K}^{+}$ions [41]. Furthermore, the addition of valinomycin, an antibiotic increasing membrane potential, resulted in a significant increase of $\operatorname{Arg}_{8}$ penetration [42].

Despite the common features of the presented models of direct translocation, attention should be paid to the different elements of these mechanisms:

- The model of the inverted micelle assumes no direct contact between the peptide and the hydrophobic components of phospholipids, which is observed for the other modes of transport without energy contribution, in which the formation of membrane pores by a change in the conformation of membrane phospholipids occurs.

- The 'toroidal' and 'carpet' models assume a significant reorganization of membrane phospholipids, as opposed to the 'barrel-stave' model, where no such significant changes across the membrane are observed.

- In the inverted cell model, interactions between CPPs and cell membranes result in the formation 
MACROPINOCYTOSIS
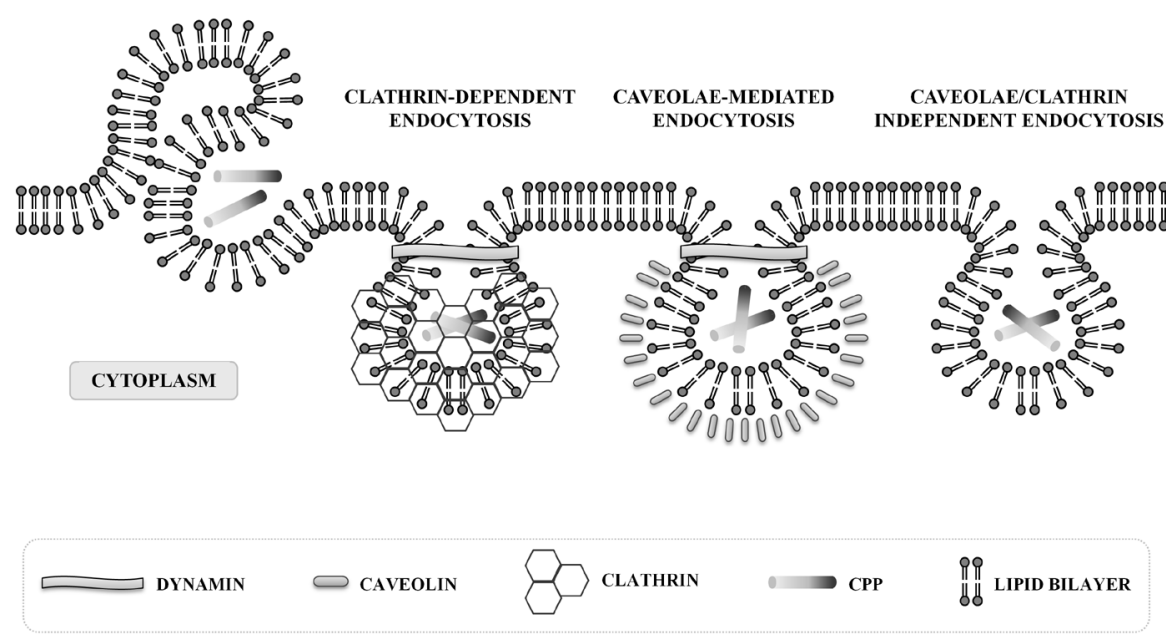

Figure 2. Proposed mechanisms of CPP translocation by endocytosis as proposed by Trabulo et al. [19]

of concave fragments of the membrane, and in the 'toroidal' model, membrane protrusions occur.

- In the 'barrel-stave' and 'toroidal' models, formation of pores within the membrane, through the homo-oligomerization of peptides introduced in the membrane, allows the prediction of well-defined structures, unlike the highly unpredictable and variable elements constituting the 'carpet' model [19].

- The driving forces of the direct translocation processes are CPP gradient for the 'toroidal' model and the inverted micelle or membrane potential in case of adaptive translocation model.

All models of direct translocation, except for the inverted micelle model, allow the transfer of large-sized particles. In addition, these models require the presence of secondary structures composed of $\alpha$-helices, which are part of many CPPs. However, regardless of the model, the translocation of large molecules requires a large destabilization of cell membrane, which is not correlated with the observed low cytotoxicity of CPPs and their conjugates. Thus, none of the presented models can fully explain the results of experiments with different CPPs, suggesting a contribution of alternative mechanisms of peptides' internalization, especially during penetration combined with molecular delivery [19].

\section{Energy-dependent endocytosis-mediated cellular uptake}

Despite the fact that results of many studies have shown the contribution of endocytosis in the CPP internalization mechanism and their cargo molecules, there are controversies surrounding the exact definition of the type of endocytosis involved in this process (Figure 2) [19]. Hence, cell biology techniques were used to determine the type of endocytosis contribution or the transport without energy contribution in the process of CPP absorption:

- incubation of cells with CPPs at low temperatures $\left(<4^{\circ} \mathrm{C}\right)$ or under energy deficiency;

- application of trypsin to remove surface receptor proteins;

- use of confocal or freeze-fracture electron microscopy [43, 44];

- incubation with compounds facilitating selective transport pathway, e.g. brefeldin A [45];

- binding to a cargo molecule determining a specific type of transport (e.g. transferrin, cholera toxin, dextran, or $\mathrm{G}$ protein) or to the target location in the cell allowing the determination of internalization type (e.g. caveolin-1 endosome antigen 1 EEA1) [46];

- overexpression of mutant genes of proteins associated with appropriate models of internalization (e.g. dynamins), which led to the exclusion of a strictly defined process from further investigations [19].

The abovementioned methods enable a more accurate determination of the complexity of the mechanisms of CPP transport into cells, depending on the amino acids sequence. It was demonstrated that the fusion peptide GST-Tat-GFP is subjected to internalization during caveolin-dependent endocytosis [47]. On the other hand, macropinocytosis, as one of the main endocytosis pathways that accompanies cell surface ruffling, was found to be the mode of CPPs cellular introduction as shown by numerous studies [48]. In turn, the native Tat protein (9837 Da), Tat PTD (1000-5000 Da) and Tat-HA2 fusion protein 
Table 2. Types of CPPs cellular introduction with cargo according to Farkhani et al. [103]

\begin{tabular}{|c|c|c|}
\hline Peptide & Cargo & Proposed uptake mechanisms \\
\hline \multirow[t]{2}{*}{ Penetratin } & Dextran & Macropinocytosis \\
\hline & PLA-PEG & Lipid raft-mediated endocytosis and direct translocation \\
\hline \multirow[t]{5}{*}{ Tat } & QDs & Macropinocytosis \\
\hline & Liposomes & Endocytic uptake through binding to HSPGs \\
\hline & Liposomes & Endocytic uptake \\
\hline & SPIONs & Endocytosis \\
\hline & Gold nanostars & Actin-driven lipid raft-mediated macropinocytosis \\
\hline \multirow[t]{2}{*}{$\operatorname{Arg}_{8}$} & \multirow{2}{*}{ Liposomes } & Vesicular transport \\
\hline & & Macropinocytosis \\
\hline
\end{tabular}

PLA-PEG — polylactic acid-polyethylene glycol; QDs — quantum dots; SPIONs — superparamagnetic iron oxide nanoparticles; PNA — peptide nucleic acid

( $>30,000 \mathrm{Da}$ ) are introduced into the cells mainly by macropinocytosis $[49,50]$. On the contrary, the results of the studies conducted by Richard et al. involving native Tat protein have led to the observation of internalization by clathrin-coated vesicles [51].

With respect to cell-penetrating peptides, it has been demonstrated that the penetration of $\mathrm{Arg}_{9}$ model peptide and other oligomers of arginine into the cell occurs via endocytosis dependent on the peptide binding to the membrane-specific heparan sulfate. Subsequently, inside endosomal vesicle, heparan sulfate may be degraded by heparanase, which leads to the dissociation of peptides, and, consequently, to the interaction of CPPs with the endosomal membrane. Finally, after destabilization of endosomal membrane, the peptides are released into the cytoplasm [52].

Thermodynamic studies have shown that paCPPs and saCPPs can penetrate into the cell interior thanks to the direct translocation at low, micromolar concentrations. In turn, naCPPs also penetrate the cell membrane at low concentrations as a result of the endocytosis [38]. However, it should be noted that depending on the experimental conditions, different mechanisms of translocation through the membrane has been reported for all CPPs.

The discrepancies between results obtained by various groups may partially result from the use of various concentrations of CPPs in different biological (i.e. cellular) models, which may cause the induction of different transportation pathways, involving the pathway which requires no energy input, as well as different types of endocytosis. Thus, for instance, higher concentrations of CPPs $(>10 \mu \mathrm{M})$ may lead to direct translocation [27, 53, 54]. Until one of the methods of cell membrane penetration is not considered to be the most dominant and reliable, it can be assumed that each of the above-described transport pathways may be involved in the penetration of CPPs depending on their concentration, hydrophobicity, or other physicochemical parameters. The method of CPP penetration into cells can also be affected by the charge type, the class of CPP, the cell line used in the experiment, and incubation conditions [55].

Different pathways of cellular introduction also depend on a cargo molecule. It was noted, that micropinocytosis is the mechanism of penetratin transport if it is conjugated with dextran [56], whereas lipid raft-mediated endocytosis and direct translocation are involved when PLA-PEG (polylactic acid-polyethylene glycol) was the cargo of penetratin [57]. Additional examples of cargomediated transport pathways are presented in Table 2.

\section{Methods of CPP conjugation with transported molecules}

Binding of CPPs with transported molecules may occur in different manners, most often by covalent bonds. In case of peptides or proteins, there is a direct binding between the transported molecule and CPP. In other cases, the use of a special linkage, the so-called linker, is recommended. The appropriate linker should be characterized by as low toxicity as possible and the ease of molecule release from the CPP after crossing the cell membrane. The role of the linker is often attributed to side chains of the residues present in CPP amino acid sequence, such as the thiol group of cysteine or the $\varepsilon$-amino group of lysine. Non-covalent interactions, such as between streptavidin and biotin attached to CPP, are also possible [45].

\section{Covalent strategy}

Introduction techniques using CPPs are mainly based on the formation of covalent bonds between the 
peptide and the molecule transported. The bond is formed by chemical binding with linker or by cloning, after which the expression of protein-bound CPP is observed [58-60]. Most studies describe the following protein-derived peptides and their derivatives used in covalent binding to the cargo molecule: Tat, penetratin, $\operatorname{Arg}_{8}$ and TP $[6,14,61,62]$.

Other protein-derived peptides such as VP22 protein from herpes simplex virus, $p V e c$, calcitonin-derived peptides, and antimicrobial peptides buforin I and SynB peptide have also found an application in order to confirm the possibility of transport of various chemical compounds covalently bound to peptides $[1,4]$. In addition, CPPs of new generation containing different motifs or transduction domains in combination with protein or oligonucleotide-binding domains have been developed [63, 64].

Disulfide and thioester bonds are mainly applied. The results of the studies suggest the possibility of application of covalent bonds for the delivery of peptide nucleic acid (PNA), PMO oligomers, peptides, and proteins [65]. The use of covalent binding has its certain advantages and disadvantages as well. The positive aspect of this method is the improvement and reproducibility of the procedures along with the control of stechiometry provided by CPP molecules.

However, from a chemical viewpoint, covalent binding of CPP to the delivered molecules is limited and also carries the risk of changes of biological activity of the molecules transported. In the case of oligonucleotides or siRNA transporting, binding to CPP may lead to the reduction of their biological properties, and therefore the use of noncovalent bonds may be more appropriate [65].

\section{Noncovalent strategy}

Binding of CPP with transported molecules by noncovalent bonds is mainly based on short amphipathic peptides consisting of two domains, hydrophilic polar and hydrophobic nonpolar. These peptides include MPG, Pep-1, MAP, SAP, and PPTG1 (see Table 1). Their amphipathic character may result from primary or secondary structure. Primary amphipathic peptides can be described as sequentially arranged subsets of domains of hydrophobic and hydrophilic residues. Secondary peptides are formed due to the conformation that enables the arrangement of hydrophobic and hydrophilic residues on opposite sides of the molecule [66].

The group of primary amphipathic peptides includes MPG and Pep-1, which contain a hydrophilic domain rich in lysine residues derived from nuclear localization signal (NLS) sequence of the SV40 virus protein. Apart from this sequence, MPG also includes the $\mathrm{N}$-terminal hydrophobic fragment derived from the gp41 of HIV protein, and the composition of Pep-1 includes the hydrophobic domain rich in tryptophan residues. For the abovementioned CPPs, both domains are connected with the domain linker providing the flexibility and cohesion between the hydrophobic and hydrophilic parts. MPG and Pep-1 form stable complexes with the transported molecules such as oligonucleotides, peptides, and proteins, via noncovalent electrostatic and hydrophobic interactions.

The efficacy of the amphipathic Pep-1 peptide in the efficient delivery of noncovalently bound peptides and proteins was demonstrated [67]. Noncovalent bonds were effective also in the case of MPG transferring siRNA into cells $[68,69]$. Moreover, the effectiveness of noncovalent bonds for such CPPs as Tat, polyarginine, TP (and its derivatives) transporting proteins or oligonucleotides has been proven [62,64]. Examples of CPP and methods of their conjugation with transported molecules were shown in Table 3.

\section{Influence of CPPs on cells and at body's level}

\section{CPP cytotoxicity in vitro}

The vast majority of studies on the toxicity of CPPs using human/mammalian cells refer to in vitro studies [70]. Comparative studies confirm the differences between cytotoxicity depending on the composition and classification of the CPPs. Thus, disruption of the integrity of the cell membrane - manifested by leakage of cytoplasmic components - by amphipathic CPPs has been correlated with their hydrophobic potential [71]. Analysis of the cytotoxicity of unmodified CPP by the measurements of a cytosolic enzyme lactate dehydrogenase (LDH) leakage, membrane depolarization with the use of $\operatorname{DiBAC}_{4}(3)$, MTT test, and the analysis of hemolysis showed relatively high cytotoxic properties of TP10 as a model amphipathic $\mathrm{CPP}$ and the average cytotoxicity of CPP representatives rich in arginine, such as Tat and penetratin [72].

In turn, studies on synthetic CPPs such as oligo -Arg, performed on mouse myoblasts showed the least, both short- and long-term, cytotoxic properties of $\mathrm{Arg}_{9}$ [70]. Hence, in the case of CPPs, decreasing sequence-dependent cytotoxicity has been postulated in an order: oligo-Arg > penetratin > Tat $[73,74]$. For TP10, the analysis of toxicity provided different results depending on the type of cell used: cervical cancer HeLa cell line was very sensitive and fibroblast cell line NIH 3T3 was relatively insensitive to the doses up to $25 \mu \mathrm{M}$ [10]. It was also observed that in vitro cytotoxicity of CPP changes significantly after the binding of transported molecules such as fluorescent 
Table 3. Examples of CPP and methods of their conjugation with transported molecules according to Kilk [104]

\begin{tabular}{|c|c|c|c|c|}
\hline Peptide & Cargo type & Specification of cargo & Type of connection & $\begin{array}{l}\text { Ratio CPP/ } \\
\text { /cargo }\end{array}$ \\
\hline Penetratin & Low molecular weight compound & Fluorophore & Covalent & 1 \\
\hline TP10 & Peptide & PKC & Disulphide & 1 \\
\hline pTat & Peptide & PKC & Disulphide & 1 \\
\hline pTat, Penetratin & Peptide & $\begin{array}{l}\text { Cyclin, cyclin-dependent } \\
\text { kinase inhibitors }\end{array}$ & $\begin{array}{l}\text { Synthesis from one } \\
\text { mRNA }\end{array}$ & 1 \\
\hline $\begin{array}{l}\text { pTat, } \operatorname{Arg}_{11} \\
\operatorname{Arg}_{9}, \operatorname{Arg}_{7}\end{array}$ & Protein & EGFP & Fusion & 1 \\
\hline Pep-1 & Protein & GFP, Pep-A & Non-covalent & $\begin{array}{l}\text { 6-8 for Pep-A } \\
12-14 \text { for GFP }\end{array}$ \\
\hline pTat and Penetratin & Protein & Avidin & Biotin-avidin & $1(4)$ \\
\hline $\operatorname{Arg}_{8}$ & Protein & $\begin{array}{l}\text { Proapoptotic protein }+ \\
\text { EGFP with His tail }\end{array}$ & $\begin{array}{l}\mathrm{Ni}^{2+}-\mathrm{His} \\
\text { (non-covalent) }\end{array}$ & 1 \\
\hline Penetratin & Oligonucleotide & Nonsense PNA & Peptide bond & 1 \\
\hline TP & Oligonucleotide & PNA for chromosome $\mathrm{X}$ & Disulphide & 1 \\
\hline pTat & Polyanion & DNA, heparan sulfate & $\begin{array}{l}\text { Interaction } \\
\text { between charges }\end{array}$ & $>7$ \\
\hline TP, TP10 & Oligonucleotide & $\begin{array}{l}\text { Target sequence for NF } \\
\text {-kappaB }\end{array}$ & $\begin{array}{l}\text { Thiol to PNA, } \\
\text { hybridization } \\
\text { between PNA- } \\
\text {-oligonucleotide }\end{array}$ & 1 \\
\hline TP & Colloidal gold & $\begin{array}{l}\text { Covalent complex } \\
\text { gold-avidin }\end{array}$ & Biotin-avidin & $1(4)$ \\
\hline pTat, longer version of NLS & Virus & Lambda phage & $\begin{array}{l}\text { Expression on } \\
\text { phage surface }\end{array}$ & ND \\
\hline
\end{tabular}

labels or other proteins [73]. For example, the toxicity of Tat fusion protein with anti-apoptotic NEMO (NF-kappaB essential modulator) domain is increased more than a hundredfold [75]. It has been proposed that binding macromolecules to CPP changes - due to the size of the complex - the mechanism of CPP internalization from direct translocation to endocytosis, which is related to the lower number of CPPs in a cell and thus lower cytotoxicity $[70,74,76]$.

Another goal of the in vitro studies is the selective binding of CPPs by different types of cells, especially, cancer cells. It was noted that due to the overexpression of CXCR4 receptor on cancer cells, CXCR4 receptor binding partner $-\operatorname{Arg}_{12}$ - showed high efficiency of penetration into tumor cells $[9,77]$. The most recent reports have suggested the selective uptake of azurin-based CPPs by breast cancer [78], melanoma [79] or lymphoma [80, 81] cells in vitro.

\section{In vivo studies of CPPs}

Similarly as for the in vitro studies, results of CPP toxicity measured in vivo are difficult to compare due to methodological differences: type of animal, route of administration, methods for determination of biological effects, the type of molecules transported, and the type of CPP [70]. For instance, Tat and penetratin conjugated with the siRNA of p38 gene, inhaled by laboratory mice, caused a transient decrease in the expression of p38 MAP kinase gene, which was observed mainly in lung macrophages and adjacent pneumocytes [82]. In Sprague Dawley rats, after intravenous administration of RXR4 fusion peptide ( $\mathrm{X}=6$-aminocaproic acid) was bound to PMO (phosphorodiamidate morpholino oligomer), a threshold below $15 \mathrm{mg} / \mathrm{kg}$ was established at which fusion CPP was not toxic, whereas the dose of $150 \mathrm{mg} / \mathrm{kg}$ was associated with adverse side effects such as lethargy, weight loss, and elevated serum creatinine [83].

Based on clinical and histological observations in BALB/c nu/nu knockout mice transplanted with pancreatic metastatic tumor cells, intravenous administration of a fusion CPP, penetratin-Grb7 peptide inhibitor at a maximum dose of $100 \mathrm{mM} / \mathrm{kg}$ every three days was recommended due to lack of toxicity at body's level [84]. In mice with colorectal tumors 
Table 4. Examples of clinical studies of the CPP conjugates usage, modified from the review by Shi et al. [89]

\begin{tabular}{|l|l|l|l|l|}
\hline Conjugate & CPP & Cargo & Disease & Clinical phase (years) \\
\hline PsorBan & Arg $_{8}$ & Cyclosporine A & Psoriasis & Phase II terminated (2003) \\
\hline RT-001 & $\begin{array}{l}\text { Lysine-rich peptides sandwiched } \\
\text { by two Tat(49-57) }\end{array}$ & Botulinum toxin type A & $\begin{array}{l}\text { Lateral canthal lines, } \\
\text { crow's feet and facial } \\
\text { wrinkles }\end{array}$ & Phase II completed (2013) \\
\hline AZX-100 & PTD4 & Heat shock protein 20 & $\begin{array}{l}\text { Scar prevention and } \\
\text { scar reduction }\end{array}$ & Phase II completed (2012) \\
\hline KAI-9803 & Tat(47-57) & Protein kinase C inhibitor & Myocardial infarction & Phase II completed (2011) \\
\hline KAI-1678 & Tat(47-57) & Protein kinase C inhibitor & Spinal cord injury & Phase II completed (2011) \\
\hline AVI-5038 & Unknown & Antisense PMO & $\begin{array}{l}\text { Duchene muscular } \\
\text { dystrophy }\end{array}$ & Preclinical (2012) \\
\hline XG-102 & Tat(48-57) & C-Jun-N-terminal kinases & Inflammation & Phase I completed (2012) \\
\hline p28 & p28 & $\begin{array}{l}\text { Also p28, a non-HDM2-me- } \\
\text { diated peptide inhibitor of } \\
\text { p53 ubiquitination }\end{array}$ & $\begin{array}{l}\text { Refractory solid tumors } \\
\text {-terminal kinases }\end{array}$ & Phase I completed (2013) \\
\hline AM111 & Tat(48-57) & $\begin{array}{l}\text { Inhibitor of C-Jun-N- } \\
\text { Hearing loss }\end{array}$ & Phase II completed (2013) \\
\hline
\end{tabular}

derived from transplanted human HCT116 cells, after injection of DA3-PEI fusion CPP conjugated with siRNA for XIAP mRNA (overexpression of XIAP was frequently noted in various types of cancer [85]), a significant reduction in tumor size was observed [86]. Recently, in vivo studies with the administration of morpholino oligos conjugated with CPPs are carried out, since they were shown to efficiently block or repair the expression of targeted genes. Morpholinos-CPPs showed efficient splice correction-therapy in Duchenne muscular dystrophy [87] (Table 4). Studies with the use of morpholinos-M12 (muscle-homing CPP) showed in about $25 \%$ of mdx deficient mice normal level of dystrophin, suggesting that M12 CPP can be efficiently used in lower than $75 \mathrm{mg} / \mathrm{kg}$ doses [88].

Another goal of CPP usage in modern medicine is vaccination. Administration of vaccines or pharmaceutical agents in lower concentrations in assistance of (or fused with) CPPs, was noted as a promising opportunity [89]. Although none of the vaccines conjugated with CPPs have passed the FDA threshold into the clinics, there are numerous ongoing preclinical and clinical evaluations of them [90]. The first CPP-pharmaceutical agent conjugate, cyclosporine-Arg ${ }_{8}\left(\right.$ PsorBan $^{\circledR}$ by Cell Gate Inc., Redwood City, CA, USA) passed clinical tests and was used for the topical therapy of psoriasis by transdermal delivery of cyclosporine A [91]. The conjugate entered Phase II clinical trial, which was eventually terminated in 2003. The modern CPP-vaccines were tested for myocardial infarction [92], spinal cord injury [93] and HIV vaccination. Other studies have been re performed in metastatic solid tumors [89] or in acute sensorineural hearing loss caused by cochlear injury [94]. Examples of CPPs conjugated with pharmaceutical agents in clinical development are shown in Table 4 [89].

CPPs were recently used for the introduction of active agents across blood-brain barrier (BBB) [95], which is normally impermeable for most of the pharmaceutical substances at non-toxic concentrations [96]. For protein introduction, administration of Tat-JNKI1 fusion protein 3 hours after brain ischemia significantly reduced the infarct volume in mice [97]. SOCS3 protein introduced with FGF4-CPP protected mice from lethal effects of staphylococcal enterotoxin B and lipopolysaccharide by reducing production of inflammatory cytokines and hemorrhagic necrosis in brain [98]. In experiments with human patients with brain metastases, efficient introduction of anti-cancer drug, paclitaxel, was observed when conjugated to Angiopep-2 CPP [99]; significant uptake of doxorubicin was noted when the drug was conjugated either with Angiopep-5 [100] or SynB1/SynB5 CPPs [95, 101].

It was noted that most cancer cells isolated from metastases are characterized by multidrug resistance. Therefore the efficient delivery of cytotoxic agents into those cells is highly required [102]. The studies of CCPs usage in the administration of anti-cancer drugs such as doxorubicin, paclitaxel, vincristine sulfate and taxol have been well-established recently [103]. Doxorubicin was conjugated to Tat, penetratin and $\operatorname{Arg}_{8}$ derivatives, whereas paclitaxel and taxol where connected to either Tatp-Cys or $\operatorname{Arg}_{8}$, respectively. The examples of in vivo studies of CPP-anticancer drug delivery have been presented by Farkhani et al. in a recent review [103]. 


\section{Conclusions}

The unique properties and the wide range of applications of cell-penetrating peptides have made this group of compounds one of the most widely studied over the past 25 years. The first discovered CPPs, such as Tat and penetratin, are still being studied as efficient cargo delivery CPPs. Despite the enormous progress in the designing and synthesis of new drugs, still most of them are not satisfactorily effective in vivo. The penetrating properties of CPPs increase the efficiency of the delivery of hydrophilic drugs and genetic material into many cell types (including brain cells) in vivo. This may lead to advances in the treatment of diseases for which, due to difficulties in drug delivery system, no effective treatment is available. However, before the CPPs could be used as drug carriers, the mechanisms of their cell membrane penetration capability as well as the efficiency, selectivity, and cost of synthesis of CPP-cargo hybrids, and above all the impact (toxicity) of CPP on living organisms should be carefully evaluated.

\section{References}

1. El-Andaloussi S, Holm T, Langel U. Cell-penetrating peptides: mechanisms and applications. Curr Pharm Des. 2005;11:3597-3611.

2. Green M, Loewenstein PM. Autonomous functional domains of chemically synthesized human immunodeficiency virus tat trans-activator protein. Cell. 1988;55:1179-1188.

3. Viscidi RP, Mayur K, Lederman HM, Frankel AD. Inhibition of antigen-induced lymphocyte proliferation by Tat protein from HIV-1. Science. 1989;246:1606-1608.

4. Joliot A, Pernelle C, Deagostini-Bazin H, Prochiantz A. Antennapedia homeobox peptide regulates neural morphogenesis. Proc Natl Acad Sci USA. 1991;88:1864-1868.

5. Derossi D, Joliot AH, Chassaing G, Prochiantz A. The third helix of the Antennapedia homeodomain translocates through biological membranes. J Biol Chem. 1994;269:10444-10450.

6. Vives E, Brodin P, Lebleu B. A truncated HIV-1 Tat protein basic domain rapidly translocates through the plasma membrane and accumulates in the cell nucleus. J Biol Chem. 1997;272:16010-16017.

7. Mae M, Langel U. Cell-penetrating peptides as vectors for peptide, protein and oligonucleotide delivery. Curr Opin Pharmacol. 2006;6:509-514.

8. El-Andaloussi S, Johansson HJ, Holm T, Langel U. A novel cell-penetrating peptide, M918, for efficient delivery of proteins and peptide nucleic acids. Mol Ther. 2007;15:1820-1826.

9. Reissmann S. Cell penetration: scope and limitations by the application of cell-penetrating peptides. J Pept Sci. 2014;20:760-784.

10. Song J, Kai M, Zhang W et al. Cellular uptake of transportan 10 and its analogs in live cells: Selectivity and structure-activity relationship studies. Peptides. 2011;32:1934-1941.

11. Zorko M, Langel U. Cell-penetrating peptides: mechanism and kinetics of cargo delivery. Adv Drug Deliv Rev. 2005;57:529-545.

12. Elmquist A, Lindgren M, Bartfai T, Langel U. VE-cadherin-derived cell-penetrating peptide, pVEC, with carrier functions. Exp Cell Res. 2001;269:237-244.
13. Madani F, Lindberg S, Langel U, Futaki S, Graslund A. Mechanisms of cellular uptake of cell-penetrating peptides. J Biophys. 2011;2011:414729.

14. Futaki S, Suzuki T, Ohashi W et al. Arginine-rich peptides. An abundant source of membrane-permeable peptides having potential as carriers for intracellular protein delivery. $J$ Biol Chem. 2001;276:5836-5840.

15. Avrahami D, Shai Y. Bestowing antifungal and antibacterial activities by lipophilic acid conjugation to D,L-amino acidcontaining antimicrobial peptides: a plausible mode of action. Biochemistry. 2003;42:14946-14956.

16. Zhang L, Torgerson TR, Liu XY et al. Preparation of functionally active cell-permeable peptides by single-step ligation of two peptide modules. Proc Natl Acad Sci USA. 1998;95:9184-9189.

17. Bleifuss E, Kammertoens T, Hutloff A et al. The translocation motif of hepatitis B virus improves protein vaccination. Cell Mol Life Sci. 2006;63:627-635.

18. Rennert R, Neundorf I, Jahnke HG et al. Generation of carrier peptides for the delivery of nucleic acid drugs in primary cells. ChemMedChem. 2008;3:241-253.

19. Trabulo S, Cardoso AL, Mano M, de Lima MC. Cell-penetrating peptides-Mechanisms of cellular uptake and generation of delivery Systems. Pharmaceuticals (Basel). 2010;3:961-993.

20. Soomets U, Lindgren $M$, Gallet $X$ et al. Deletion analogues of transportan. Biochim Biophys Acta. 2000;1467:165-176.

21. Radis-Baptista G, Kerkis I. Crotamine, a small basic polypeptide myotoxin from rattlesnake venom with cell-penetrating properties. Curr Pharm Des. 2011;17:4351-4361.

22. Wender PA, Mitchell DJ, Pattabiraman K, Pelkey ET, Steinman L, Rothbard JB. The design, synthesis, and evaluation of molecules that enable or enhance cellular uptake: peptoid molecular transporters. Proc Natl Acad Sci USA. 2000;97:13003-13008.

23. Huq I, Ping YH, Tamilarasu N, Rana TM. Controlling human immunodeficiency virus type 1 gene expression by unnatural peptides. Biochemistry. 1999;38:5172-5177.

24. Derossi D, Calvet S, Trembleau A, Brunissen A, Chassaing G, Prochiantz A. Cell internalization of the third helix of the Antennapedia homeodomain is receptor-independent. J Biol Chem. 1996;271:18188-18193.

25. Matsuzaki K, Yoneyama S, Murase O, Miyajima K. Transbilayer transport of ions and lipids coupled with mastoparan $\mathrm{X}$ translocation. Biochemistry. 1996;35:8450-8456.

26. Deshayes S, Morris MC, Divita G, Heitz F. Interactions of amphipathic CPPs with model membranes. Biochim Biophys Acta. 2006;1758:328-335.

27. Duchardt F, Fotin-Mleczek M, Schwarz H, Fischer R, Brock R. A comprehensive model for the cellular uptake of cationic cell-penetrating peptides. Traffic. 2007;8:848-866.

28. Kosuge M, Takeuchi T, Nakase I, Jones AT, Futaki S. Cellular internalization and distribution of arginine-rich peptides as a function of extracellular peptide concentration, serum, and plasma membrane associated proteoglycans. Bioconjug Chem. 2008;19:656-664.

29. Berlose JP, Convert O, Derossi D, Brunissen A, Chassaing G. Conformational and associative behaviours of the third helix of antennapedia homeodomain in membrane-mimetic environments. Eur J Biochem. 1996;242:372-386.

30. Binder H, Lindblom G. A molecular view on the interaction of the trojan peptide penetratin with the polar interface of lipid bilayers. Biophys J. 2004;87:332-343.

31. Ziegler A, Blatter XL, Seelig A, Seelig J. Protein transduction domains of HIV-1 and SIV TAT interact with charged lipid 
vesicles. Binding mechanism and thermodynamic analysis. Biochemistry. 2003;42:9185-9194.

32. Astriab-Fisher A, Sergueev D, Fisher M, Shaw BR, Juliano RL. Conjugates of antisense oligonucleotides with the Tat and antennapedia cell-penetrating peptides: effects on cellular uptake, binding to target sequences, and biologic actions. Pharm Res. 2002;19:744-754.

33. Lindberg M, Jarvet J, Langel U, Graslund A. Secondary structure and position of the cell-penetrating peptide transportan in SDS micelles as determined by NMR. Biochemistry. 2001;40:3141-3149.

34. Dathe M, Wieprecht T. Structural features of helical antimicrobial peptides: their potential to modulate activity on model membranes and biological cells. Biochim Biophys Acta. 1999;1462:71-87.

35. Yang L, Harroun TA, Weiss TM, Ding L, Huang HW. Barrel-stave model or toroidal model? A case study on melittin pores. Biophys J. 2001;81:1475-1485.

36. Lundberg P, Langel U. A brief introduction to cell-penetrating peptides. J Mol Recognit. 2003;16:227-233.

37. Mishra A, Gordon VD, Yang L, Coridan R, Wong GC. HIV TAT forms pores in membranes by inducing saddle-splay curvature: potential role of bidentate hydrogen bonding. Angew Chem Int Ed Engl. 2008;47:2986-2989.

38. Ziegler A. Thermodynamic studies and binding mechanisms of cell-penetrating peptides with lipids and glycosaminoglycans. Adv Drug Deliv Rev. 2008;60:580-597.

39. Mitchell DJ, Kim DT, Steinman L, Fathman CG, Rothbard JB. Polyarginine enters cells more efficiently than other polycationic homopolymers. J Pept Res. 2000;56:318-325.

40. Herce HD, Garcia AE. Molecular dynamics simulations suggest a mechanism for translocation of the HIV-1 TAT peptide across lipid membranes. Proc Natl Acad Sci USA. 2007;104:20805-20810.

41. Bjorklund J, Biverstahl H, Graslund A, Maler L, Brzezinski P. Real-time transmembrane translocation of penetratin driven by light-generated proton pumping. Biophys J. 2006;91:29-31.

42. Rothbard JB, Jessop TC, Lewis RS, Murray BA, Wender PA. Role of membrane potential and hydrogen bonding in the mechanism of translocation of guanidinium-rich peptides into cells. J Am Chem Soc. 2004;126:9506-9507.

43. Richard JP, Melikov K, Vives E et al. Cell-penetrating peptides. A reevaluation of the mechanism of cellular uptake. J Biol Chem. 2003;278:585-590.

44. Afonin S, Frey A, Bayerl S et al. The cell-penetrating peptide TAT(48-60) induces a non-lamellar phase in DMPC membranes. Chemphyschem. 2006;7:2134-2142.

45. Wierzbicki PM, Kogut M, Ruczynski J et al. Protein and siRNA delivery by transportan and transportan 10 into colorectal cancer cell lines. Folia Histochem Cytobiol. 2014;4. doi: 10.5603/FHC.a2014.0035.

46. Petrescu AD, Vespa A, Huang H, McIntosh AL, Schroeder F, Kier AB. Fluorescent sterols monitor cell penetrating peptide Pep-1 mediated uptake and intracellular targeting of cargo protein in living cells. Biochim Biophys Acta. 2009; 1788:425-441

47. Ferrari A, Pellegrini V, Arcangeli C, Fittipaldi A, Giacca M, Beltram F. Caveolae-mediated internalization of extracellular HIV-1 tat fusion proteins visualized in real time. Mol Ther. 2003;8:284-294.

48. Jiang Y, Li M, Zhang Z, Gong T, Sun X. Cell-penetrating peptides as delivery enhancers for vaccine. Curr Pharm Biotechnol. 2014;15:256-266.

49. Kaplan IM, Wadia JS, Dowdy SF. Cationic TAT peptide transduction domain enters cells by macropinocytosis. J Control Release. 2005;102:247-253.
50. Gump JM, June RK, Dowdy SF. Revised role of glycosaminoglycans in TAT protein transduction domain-mediated cellular transduction. J Biol Chem. 2010;285:1500-1507.

51. Richard JP, Melikov K, Brooks H, Prevot P, Lebleu B, Chernomordik LV. Cellular uptake of unconjugated TAT peptide involves clathrin-dependent endocytosis and heparan sulfate receptors. J Biol Chem. 2005;280:15300-15306.

52. Futaki S, Niwa M, Nakase I et al. Arginine carrier peptide bearing $\mathrm{Ni}(\mathrm{II})$ chelator to promote cellular uptake of histidine-tagged proteins. Bioconjug Chem. 2004;15:475-481.

53. Tunnemann G, Martin RM, Haupt S, Patsch C, Edenhofer F, Cardoso MC. Cargo-dependent mode of uptake and bioavailability of TAT-containing proteins and peptides in living cells. FASEB J. 2006;20:1775-1784

54. Dupont E, Prochiantz A, Joliot A. Identification of a signal peptide for unconventional secretion. J Biol Chem. 2007;282:8994-9000.

55. Vives E, Schmidt J, Pelegrin A. Cell-penetrating and cell -targeting peptides in drug delivery. Biochim Biophys Acta. 2008;1786:126-138.

56. Amand HL, Fant K, Norden B, Esbjorner EK. Stimulated endocytosis in penetratin uptake: effect of arginine and lysine. Biochem Biophys Res Commun. 2008;371:621-625.

57. Xia $\mathrm{H}, \mathrm{Gao} \mathrm{X}, \mathrm{Gu} \mathrm{G}$ et al. Penetratin-functionalized PEG-PLA nanoparticles for brain drug delivery. Int J Pharm. 2012;436:840-850.

58. Gait MJ. Peptide-mediated cellular delivery of antisense oligonucleotides and their analogues. Cell Mol Life Sci. 2003;60:844-853.

59. Moulton HM, Nelson MH, Hatlevig SA, Reddy MT, Iversen PL. Cellular uptake of antisense morpholino oligomers conjugated to arginine-rich peptides. Bioconjug Chem. 2004;15: 290-299.

60. Zatsepin TS, Turner JJ, Oretskaya TS, Gait MJ. Conjugates of oligonucleotides and analogues with cell penetrating peptides as gene silencing agents. Curr Pharm Des. 2005;11: 3639-3654.

61. Futaki S, Ohashi W, Suzuki T et al. Stearylated arginine-rich peptides: a new class of transfection systems. Bioconjug Chem. 2001;12:1005-1011.

62. Pooga M, Soomets U, Hallbrink $M$ et al. Cell penetrating PNA constructs regulate galanin receptor levels and modify pain transmission in vivo. Nat Biotechnol. 1998;16:857-861.

63. Abes R, Arzumanov AA, Moulton HM et al. Cell-penetrating-peptide-based delivery of oligonucleotides: an overview. Biochem Soc Trans. 2007;35:775-779.

64. Meade BR, Dowdy SF. Exogenous siRNA delivery using peptide transduction domains/cell penetrating peptides. $A d v$ Drug Deliv Rev. 2007;59:134-140.

65. Juliano R, Alam MR, Dixit V, Kang H. Mechanisms and strategies for effective delivery of antisense and siRNA oligonucleotides. Nucleic Acids Res. 2008;36:4158-4171.

66. Deshayes S, Morris MC, Divita G, Heitz F. Cell-penetrating peptides: tools for intracellular delivery of therapeutics. Cell Mol Life Sci. 2005;62:1839-1849.

67. Chugh A, Amundsen E, Eudes F. Translocation of cell-penetrating peptides and delivery of their cargoes in triticale microspores. Plant Cell Rep. 2009;28:801-810.

68. Simeoni F, Morris MC, Heitz F, Divita G. Insight into the mechanism of the peptide-based gene delivery system MPG: implications for delivery of siRNA into mammalian cells. Nucleic Acids Res. 2003;31:2717-2724.

69. Morris MC, Deshayes S, Heitz F, Divita G. Cell-penetrating peptides: from molecular mechanisms to therapeutics. Biol Cell. 2008;100:201-217. 
70. Tünnemann G. Toxicity, uptake and applications of intracellular delivery by cell penetrating peptides. München: Fakultät für Biologie, Ludwig-Maximilians-Universität; 2009.

71. Hallbrink M, Floren A, Elmquist A, Pooga M, Bartfai T, Langel U. Cargo delivery kinetics of cell-penetrating peptides. Biochim Biophys Acta. 2001;1515:101-109.

72. Saar K, Lindgren M, Hansen M, et al. Cell-penetrating peptides: a comparative membrane toxicity study. Anal Biochem. 2005;345:55-65.

73. Jones SW, Christison R, Bundell $\mathrm{K}$ et al. Characterisation of cell-penetrating peptide-mediated peptide delivery. $\mathrm{Br} J$ Pharmacol. 2005;145:1093-1102.

74. El-Andaloussi S, Jarver P, Johansson HJ, Langel U. Cargo-dependent cytotoxicity and delivery efficacy of cell-penetrating peptides: a comparative study. Biochem J. 2007;407:285-292.

75. Cardozo AK, Buchillier V, Mathieu M et al. Cell-permeable peptides induce dose- and length-dependent cytotoxic effects. Biochim Biophys Acta. 2007;1768:2222-2234.

76. Silhol M, Tyagi M, Giacca M, Lebleu B, Vives E. Different mechanisms for cellular internalization of the HIV-1 Tat-derived cell penetrating peptide and recombinant proteins fused to Tat. Eur J Biochem. 2002;269:494-501.

77. Snyder EL, Saenz CC, Denicourt C et al. Enhanced targeting and killing of tumor cells expressing the CXC chemokine receptor 4 by transducible anticancer peptides. Cancer Res. 2005;65:10646-10650.

78. Bernardes N, Ribeiro AS, Abreu S et al. High-throughput molecular profiling of a P-cadherin overexpressing breast cancer model reveals new targets for the anti-cancer bacterial protein azurin. Int J Biochem Cell Biol. 2014;50:1-9.

79. Zhang Y, Xia L, Zhang X, Ding X, Yan F, Wu F. Escherichia coli Nissle 1917 targets and restrains mouse B16 melanoma and 4T1 breast tumors through expression of azurin protein. Appl Environ Microbiol. 2012;78:7603-7610.

80. Ramachandran S, Mandal M. Induction of apoptosis of azurin synthesized from $P$. aeruginosa MTCC 2453 against Dalton's lymphoma ascites model. Biomed Pharmacother. 2011;65:461-466.

81. Bernardes N, Ribeiro AS, Abreu S et al. The bacterial protein azurin impairs invasion and FAK/Src signaling in P-cadherin-overexpressing breast cancer cell models. PLoS One. 2013;8:e69023.

82. Moschos SA, Jones SW, Perry MM et al. Lung delivery studies using siRNA conjugated to TAT(48-60) and penetratin reveal peptide induced reduction in gene expression and induction of innate immunity. Bioconjug Chem. 2007;18:1450-1459.

83. Amantana A, Moulton HM, Cate ML et al. Pharmacokinetics, biodistribution, stability and toxicity of a cell-penetrating peptide-morpholino oligomer conjugate. Bioconjug Chem. 2007;18:1325-1331

84. Tanaka S, Pero SC, Taguchi K et al. Specific peptide ligand for Grb7 signal transduction protein and pancreatic cancer metastasis. J Natl Cancer Inst. 2006;98:491-498.

85. Krajewska M, Kim H, Kim C et al. Analysis of apoptosis protein expression in early-stage colorectal cancer suggests opportunities for new prognostic biomarkers. Clin Cancer Res. 2005;11:5451-5461.

86. Jang YL, Yun UJ, Lee MS et al. Cell-penetrating peptide mimicking polymer-based combined delivery of paclitaxel and siRNA for enhanced tumor growth suppression. Int $J$ Pharm. 2012;434:488-493.
87. Moulton HM. Cell-penetrating peptides enhance systemic delivery of antisense morpholino oligomers. Methods $\mathrm{Mol}$ Biol. 2012;867:407-414.

88. Gao X, Zhao J, Han G et al. Effective dystrophin restoration by a novel muscle-homing peptide-morpholino conjugate in dystrophin-deficient mdx mice. Mol Ther. 2014;22:1333-1341.

89. Shi NQ, Qi XR, Xiang B, Zhang Y. A survey on "Trojan Horse" peptides: Opportunities, issues and controlled entry to "Troy". J Control Release. 2014;194C:53-70.

90. Johnson RM, Harrison SD, Maclean D. Therapeutic applications of cell-penetrating peptides. Methods Mol Biol. 2011;683:535-551.

91. Lebleu B, Moulton HM, Abes R et al. Cell penetrating peptide conjugates of steric block oligonucleotides. Adv Drug Deliv Rev. 2008;60:517-529.

92. Miyaji Y, Walter S, Chen L et al. Distribution of KAI-9803, a novel delta-protein kinase $\mathrm{C}$ inhibitor, after intravenous administration to rats. Drug Metab Dispos. 2011;39:1946-1953.

93. Cousins MJ, Pickthorn K, Huang S, Critchley L, Bell G. The safety and efficacy of KAI-1678- an inhibitor of epsilon protein kinase $\mathrm{C}$ (epsilonPKC)-versus lidocaine and placebo for the treatment of postherpetic neuralgia: a crossover study design. Pain Med. 2013;14:533-540.

94. Omotehara Y, Hakuba N, Hato N, Okada M, Gyo K. Protection against ischemic cochlear damage by intratympanic administration of AM-111. Otol Neurotol. 2011;32:1422-1427.

95. Zou LL, Ma JL, Wang T, Yang TB, Liu CB. Cell-penetrating Peptide-mediated therapeutic molecule delivery into the central nervous system. Curr Neuropharmacol. 2013;11:197-208.

96. Cecchelli R, Berezowski V, Lundquist $\mathrm{S}$ et al. Modelling of the blood-brain barrier in drug discovery and development. Nat Rev Drug Discov. 2007;6:650-661.

97. Aarts M, Liu Y, Liu L et al. Treatment of ischemic brain damage by perturbing NMDA receptor- PSD-95 protein interactions. Science. 2002;298:846-850.

98. Jo D, Liu D, Yao S, Collins RD, Hawiger J. Intracellular protein therapy with SOCS3 inhibits inflammation and apoptosis. Nat Med. 2005;11:892-898.

99. Kurzrock R, Gabrail N, Chandhasin C et al. Safety, pharmacokinetics, and activity of GRN1005, a novel conjugate of angiopep-2, a peptide facilitating brain penetration, and paclitaxel, in patients with advanced solid tumors. Mol Cancer Ther. 2012;11:308-316.

100. Che C, Yang G, Thiot C et al. New Angiopep-modified doxorubicin (ANG1007) and etoposide (ANG1009) chemotherapeutics with increased brain penetration. $\mathrm{J} \mathrm{Med}$ Chem. 2010;53:2814-2824.

101. Drin G, Cottin S, Blanc E, Rees AR, Temsamani J. Studies on the internalization mechanism of cationic cell-penetrating peptides. J Biol Chem. 2003;278:31192-31201.

102. Pauwels EK, Erba P, Mariani G, Gomes CM. Multidrug resistance in cancer: its mechanism and its modulation. Drug News Perspect. 2007;20:371-377.

103. Farkhani SM, Valizadeh A, Karami H, Mohammadi S, Sohrabi N, Badrzadeh F. Cell penetrating peptides: efficient vectors for delivery of nanoparticles, nanocarriers, therapeutic and diagnostic molecules. Peptides. 2014;57:78-94.

104. Kilk K. Cell-penetrating peptides and bioactive cargoes. Strategies and mechanisms. Stockholm: Department of Neurochemistry and Neurotoxicology Arrhenius Laboratories for Natural Sciences, Stockholm University; 2004.

Submitted: 17 December, 2014

Accepted after reviews: 19 December, 2014 Available as AoP: 19 December, 2014 